\title{
Effect of Maternal Age on Pregnancy Outcome and Cesarean Delivery Rate
}

\author{
Ali Ramazan Benlia, f, Neriman Cetin Benli ${ }^{b}$, Abdullah Taner Usta ${ }^{c}$, Tolga Atakuld ${ }^{\mathrm{d}}$, Mustafa Koroglu ${ }^{\mathrm{e}}$
}

\begin{abstract}
Background: The aims of this retrospective study were to evaluate the maternal and prenatal outcomes between 35 years and older pregnancies and younger pregnancies, and the effects of the age of pregnancy, mother and newborn.

Methods: Pregnant women who gave birth in Vakif Gureba Training and Research Hospital, Clinic of Obstetrics and Gynecology in 2006 were retrospectively screened. Pregnant women aged 35 years and over were included in this study and the pregnant women between age range of $30-34$ years were included in the control group.
\end{abstract}

Results: Pregnancy rate was found as $7.1 \%$ in 35 years and older women in all the deliveries, cesarean delivery rate was found as $46.1 \%$ in this group at 1 year period. However, cesarean delivery rate was $40.9 \%$ in the control group. Cesarean delivery rate was found as $31.6 \%$ in all the deliveries. The most common cause of cesarean section indication was fetal distress in advanced maternal age (AMA) (11.7\%), whereas previous cesarean section was found as the most common cause in the control group (15.1\%).

Conclusion: No significant difference was found between AMA group and normal pregnancies in terms of preterm labor, caesarian section, morbidity, mortality and chronic diseases such as hypertension and diabetes mellitus.

Keywords: Advanced maternal age; Obstetric outcomes; Cesarean

Manuscript accepted for publication July 04, 2014

aDepartment of Family Medicine, Faculty of Medicine, Karabuk University, Karabuk, Turkey

baglar ASM, Safranbolu, Karabuk, Turkey

'Department of Gynecology and Obstetrics, Bagcilar Education and Research Hospital, Istanbul, Turkey

${ }^{\mathrm{d}}$ Department of Gynecology and Obstetrics, Karabuk Education and Research Hospital, Karabuk, Turkey

eDepartment of Hematology, Karabuk Education and Research Hospital, Karabuk, Turkey

fCorresponding Author: Ali Ramazan Benli, Department of Family Medicine, Faculty of Medicine, Karabuk University, Karabuk, Turkey.

Email: dralibenli@gmail.com

doi: http://dx.doi.org/10.14740/jocmr1904w delivery

\section{Introduction}

Advanced maternal age (AMA) is defined as age $\geq 35$ years old at the time of delivery and is considered to be among the risky pregnancies. As of $2009,14 \%$ of all the children were born by 35 years and older mothers [1]. Pregnancies of high risk have increased mortality and morbidity for both mother and fetus during birth [2]. Several conditions such as stress, fatigue, posture of working, sight working, early or AMA, exposure to chemicals and socioeconomic status lead to an additional burden on working pregnant women [3]. Today, prolonged education, career priority, fertility control through effective contraceptive methods, heavy working conditions and economic problems lead to postponed pregnancy age $[4,5]$.

In this study, we investigated and compared maternal, perinatal and newborn outcomes of pregnancy age of younger and older than 35 years.

\section{Material and Methods}

All pregnant women who gave birth in 2006 in the Department of Obstetrics and Gynecology of Vakif Gureba Training and Research Hospital, were retrospectively investigated. Pregnant women aged 35 years and older were grouped for study group (group 1) and between ages of 30 and 34 years (group 2) were included as a control group.

Parameters which are compared between study and control groups are as follows: perinatal and obstetric complications, maternal and fetal mortality and morbidity rates, Apgar scores, gestational diabetes mellitus, early membrane rupture, preterm birth, intrauterine growth retardation (IUGR), delivery method, frequency of newborn anomalies, presence of eclampsia and preeclampsia, frequency of additional diseases, birth weight, hemoglobin values and smoking status.

\section{Statistical analysis}

Data from this study were analyzed using SPSS for Windows 
Table 1. Cesarean Delivery Rates

\begin{tabular}{llll} 
& $\mathbf{3 0}-\mathbf{3 4}$ years old & $\mathbf{2} \mathbf{3 5}$ years old & All deliveries \\
\hline Cesarean delivery rate & $40.90 \%$ & $46.10 \%$ & $31.60 \%$ \\
\hline
\end{tabular}

Table 2. Rates of Cesarean Delivery Indications

\begin{tabular}{lll}
\hline Indication for cesarean delivery & $\mathbf{3 0} \mathbf{- 3 4}$ years old & $\mathbf{2 3 5}$ years old \\
\hline Fetal distress & 5.4 & 11.7 \\
Previous cesarean delivery & 15.1 & 10.4 \\
Cephalopelvic disproportion & 2.7 & 0 \\
Malpresentation & 4.0 & 7.1 \\
Labor dystocia & 3.4 & 3.2 \\
Placenta previa & 2.0 & 2.6 \\
Abruptio placentae & 0.7 & 3.2 \\
Vasa praevia & 1.0 & 0 \\
Large birth weight & 1.7 & 1.3 \\
Precious baby & 2.3 & 1.3 \\
Oligohydramnios & 3.4 & 3.9 \\
Other & 2.7 & 4.5 \\
\hline
\end{tabular}

version 16.0 software. Student's $t$, Fisher exact, Mann-Whitney $\mathrm{U}$ and Chi-square tests were used for comparisons of study and control groups' data. $\mathrm{P}$ values $<0.05$ were considered statistically significant.

\section{Results}

Of the 2,162 pregnant women who presented to our clinic, 154 $(7.12 \%)$ were $\geq 35$ years old, while $298(13.7 \%)$ were in the age range of 30 - 34 years.

The pregnancy rate of women aged $\geq 35$ years was found to be $7.12 \%$. The cesarean delivery rate in this group was $46.1 \%$ whereas the cesarean delivery rate was $40.9 \%$ in the control group. The cesarean delivery rate was found to be $31.6 \%$ in all the deliveries (Table 1). The most common indication for cesarean delivery was fetal distress in the AMA group $(11.7 \%)$, whereas the most common indication in the control group (15.1\%) was a previous cesarean delivery (Table 2). Ratio of gestational diabetes mellitus (GDM) was $6.5 \%$ in the study group and was $3.4 \%$ in the control group, although this difference was not statistically significant (Table 3) $(\mathrm{P}>$ $0.05)$. No statistically significance difference was observed in the incidence of early membrane rupture (EMR), preterm birth and IUGR (Table 3$)(\mathrm{P}>0.05)$. No statistical significance was

Table 3. Rates of GDM, EMR, Preterm Labor and IUGR

\begin{tabular}{|c|c|c|c|c|c|c|}
\hline \multirow{2}{*}{ Age } & \multicolumn{2}{|c|}{30 - 34 years } & \multicolumn{2}{|c|}{35 years and older } & \multirow{2}{*}{ Chi-square } & \multirow{2}{*}{$\mathbf{P}$} \\
\hline & $\mathbf{n}$ & $\%$ & $\mathbf{n}$ & $\%$ & & \\
\hline \multicolumn{7}{|c|}{ Gestational diabetes mellitus } \\
\hline No & 288 & 96.6 & 144 & 93.5 & & \\
\hline Yes & 10 & 3.4 & 10 & 6.5 & 2.36 & 0.124 \\
\hline \multicolumn{7}{|c|}{ Early membrane rupture } \\
\hline No & 290 & 97.3 & 153 & 99.4 & & \\
\hline Yes & 8 & 2.7 & 1 & 0.6 & & 0.176 \\
\hline \multicolumn{7}{|c|}{ Preterm labor } \\
\hline No & 278 & 93.3 & 145 & 94.2 & & \\
\hline Yes & 20 & 6.7 & 9 & 5.8 & 0.12 & 0.721 \\
\hline \multicolumn{7}{|c|}{ Intrauterine growth retardation } \\
\hline No & 287 & 96.3 & 152 & 98.7 & & \\
\hline Yes & 11 & 3.7 & 2 & 1.3 & & 0.235 \\
\hline
\end{tabular}


Table 4. Perinatal Mortality Rates

\begin{tabular}{|c|c|c|c|c|c|c|}
\hline \multirow{2}{*}{ Age } & \multicolumn{2}{|c|}{30 - 34 years } & \multicolumn{2}{|c|}{35 years and older } & \multirow{2}{*}{ Chi-square } & \multirow{2}{*}{$\mathbf{P}$} \\
\hline & $\mathrm{n}$ & $\%$ & $\mathrm{n}$ & $\%$ & & \\
\hline \multicolumn{7}{|l|}{ Mortality } \\
\hline No & 286 & 96.0 & 149 & 96.8 & & \\
\hline Yes & 12 & 4.0 & 4 & 2.6 & 0.60 & 0.436 \\
\hline \multicolumn{7}{|l|}{ Mortality yes } \\
\hline Baby & 12 & 4.0 & 4 & 2.6 & & \\
\hline Mother & 0 & 0 & 1 & 0.6 & & \\
\hline
\end{tabular}

found between the study and control groups in terms of mortality and anemia (Table 4, 5) $(\mathrm{P}>0.05)$.

Since the normal values in the table were significant, mortality values were combined as "yes" or "no" and calculated again.

The incidence of preconceptual chronic diseases was $21.4 \%$ in the pregnant women aged $\geq 35$ years and $16.1 \%$ in the controls, although this difference was not statistically significant (Table 6) $(\mathrm{P}>0.05)$.

Difference between study and control groups was not significant for preeclampsia rates $(2.0 \%$ and $2.7 \%$ respectively; $\mathrm{P}=0.756)$.

The numbers of gravida and parity were found to be significantly higher in study group, while no significant difference was found between groups in terms of abortion rates, gestational age, mean birth weight, anemia and the first minute Apgar scores (Table 7).

No statistically significant difference was found in terms of hemoglobin values studied in patients with anemia (Table 7) $(\mathrm{P}>0.05)$.

\section{Discussion}

Pregnancy is considered as a physiological and unique period in women's life. However, an unpredictable disease of mother or fetus may complicate the pregnancy. Pregnancy is defined as "high-risk" if the possibility of an adverse outcome is higher than in the general population [6].

A high-risk pregnancy is a physiological, social and emo- tional condition, which threatens maternal and fetal health and increases the rates of mortality and morbidity [7]. Morbidity and mortality rates increase in antenatal, prenatal and postnatal periods in high-risk pregnancies compared to normal-risk pregnancies [2].

There are numerous studies about the effect of maternal age on pregnancy as a risk factor. Although recent studies have focused on the pregnancies of $\geq 35$ years [8-10], there are several studies conducted, evaluating the pregnancies of women $\geq 40$ years, even 45 years old as a standalone risk factor $[5,11]$. Today, especially in the developed countries, many women postpone having children to the fourth decades of their lives due to social, economic and educational reasons. This condition takes place in an increasing manner day by day through global population [4]. Increasing birth rate of AMA ( $\geq$ 35 years) women in developed countries is a result of couples postponing marriage and child bearing [12-14]. Because of this changing trend to give birth, it is a contradictory question that who is under risk [15]. Despite numerous definitions for "elderly gravida", this term is widely used for the women who have babies after the age of 35 [16]. However, some scientists who are working on 45 and higher aged women prefer to give definition of "very advanced maternity age" to women which are above 45 of age $[12,13]$.

Primigravid-infertile women constitute the biggest group of very advanced maternity aged women owing to advanced reproductive technologies. Modern infertility treatment methods, including oocyte donation and modern infertility treatment methods increase the number of women becoming pregnant in advanced ages [17-19]. These pregnancies are problematic

Table 5. Rates of Congenital Anomalies

\begin{tabular}{|c|c|c|c|c|c|}
\hline \multirow{2}{*}{ Age } & \multicolumn{2}{|c|}{30 - 34 years } & \multicolumn{2}{|c|}{35 years and older } & \multirow{2}{*}{$\mathbf{P}$} \\
\hline & $\mathbf{n}$ & $\%$ & $\mathbf{n}$ & $\%$ & \\
\hline \multicolumn{6}{|l|}{ Anomaly } \\
\hline No & 293 & 98.3 & 152 & 98.7 & \\
\hline Yes & 5 & 1.7 & 2 & 1.3 & 0.554 \\
\hline \multicolumn{6}{|l|}{ Anomaly yes } \\
\hline CNS anomaly & 3 & 1.0 & 1 & 0.6 & \\
\hline Extremity & 1 & 0.3 & - & - & \\
\hline Other & 1 & 0.3 & 1 & 0.6 & \\
\hline
\end{tabular}

CNS: central nervous system. 
Table 6. Preconceptional Comorbidity and Preeclampsia Rates

\begin{tabular}{|c|c|c|c|c|c|c|}
\hline \multirow{2}{*}{ Age } & \multicolumn{2}{|c|}{30 - 34 years } & \multicolumn{2}{|c|}{$\geq 35$ years old } & \multirow{2}{*}{ Chi-square } & \multirow{2}{*}{$\mathbf{P}$} \\
\hline & $\mathbf{n}$ & $\%$ & $\mathbf{n}$ & $\%$ & & \\
\hline \multicolumn{7}{|l|}{ Comorbidity } \\
\hline No & 250 & 83.9 & 121 & 78.6 & & \\
\hline Yes & 48 & 16.1 & 33 & 21.4 & 1.95 & 0.162 \\
\hline \multicolumn{7}{|l|}{ Comorbidity yes } \\
\hline Diabetes mellitus & 2 & 0.7 & 3 & 1.9 & & \\
\hline Hypertension & 3 & 1.0 & 8 & 5.2 & & \\
\hline Asthma & 13 & 4.4 & 5 & 3.2 & & \\
\hline Cardiac & 8 & 2.7 & 5 & 3.2 & & \\
\hline Other & 22 & 7.4 & 12 & 7.8 & & \\
\hline \multicolumn{7}{|l|}{ Preeclampsia } \\
\hline No & 289 & 97.3 & 150 & 98.0 & & \\
\hline Yes & 8 & 2.7 & 3 & 2.0 & & 0.756 \\
\hline
\end{tabular}

since they have to cope with chronic disease of advanced age. Problems of these pregnancies include complications related to chronic diseases as well as AMA. Medical conditions like hypertension and diabetes are more common in women who become pregnant in advanced ages. Even healthy women aged $\geq 35$ years have a higher risk of developing hypertension and diabetes during pregnancy [1]. Results of 154 pregnant women aged $\geq 35$ were analyzed in our study group. A total of 298 pregnant women in the age range of 30 - 34 were included in our study as the control group. As it was expected, pregnancy (gravida) and the number of birth (parity) were found to be higher in the study group than in the control group due to difference of age. This difference was statistically significant (Table 7).

An increase was observed in the cesarean delivery rate, which is consistent with the literature about AMA [18, 19]. In the general population, the cesarean delivery rate was $31.6 \%$, in pregnant women in the age range of $30-34$, the rate was $40.9 \%$ and in pregnancies aged $\geq 35$ years, the rate was $46.1 \%$ (Table 1). In a study by Hoque et al with 341 advanced maternal aged women, the rate of cesarean delivery was $38.4 \%$ [20].
In a meta-analysis by Smith et al with 297,842 women, in 2012 the rate of cesarean delivery was $25.7 \%$ in women $\geq 35$ years old [10]. The most common indication of cesarean delivery was fetal distress in AMA (11.7\%) and previous cesarean delivery $(15.1 \%)$ in the control group (Table 2 ).

In our study, preconceptual comorbidities were found in $21.4 \%$ of the study and in $16.1 \%$ of the control group (Table 6). Increasing of diseases emerges in the older group due to several risk factors caused by aging process. Chronic hypertension was the most common comorbidity seen in study group, while asthma was the dominant comorbidity in control group. According to literature, it has been proposed that hypertension, and some other chronic diseases have been observed more with aging; however, perinatal complications could not be explained by this assumption [21].

Despite the literature which reported an increase in gestational diabetes with AMA, no significant difference was found in our study [5, 21-23] (Table 3).

In the published papers, preeclampsia was found to increase in the beginning and end of the reproductive period. In a retrospective study by Hoque et al, a statistically significant

Table 7. Gravida, Parity, Abortions, Birth Weight of Newborn, Maternal Hemoglobin Values and First Minute Apgar Scores

\begin{tabular}{|c|c|c|c|c|c|}
\hline \multirow{2}{*}{ Age } & \multicolumn{2}{|c|}{30 - 34 years } & \multicolumn{2}{|c|}{$\geq 35$ years and older } & \multirow{2}{*}{$\mathbf{P}$} \\
\hline & Mean & SD & Mean & SD & \\
\hline Gravida & 3.35 & 1.78 & 4.77 & 2.50 & 0 \\
\hline Parity & 1.86 & 1.45 & 3.06 & 2.11 & 0 \\
\hline Abortions & 0.49 & 0.91 & 0.68 & 1.03 & 0.055 \\
\hline Live born & 1.78 & 1.35 & 2.87 & 1.88 & 0 \\
\hline Gestational age & 38.36 & 3.34 & 38.21 & 3.35 & 0.649 \\
\hline Birth weight & $3,204.73$ & 709.72 & $3,201.49$ & 734.47 & 0.964 \\
\hline Hemoglobin & 11.52 & 1.563 & 11.319 & 1.411 & 0.181 \\
\hline Apgar scores & 7.71 & 2.11 & 7.61 & 1.98 & 0.623 \\
\hline
\end{tabular}


correlation was found between the AMA and low birth weight as a result of diabetes, preeclampsia and placenta previa [20]. On the contrary, in our study, in terms of preeclampsia no significant difference was observed in our study between the study and control groups.

There is not any evidence in the literature suggesting an increase in the rate of mortality in the pregnant women aged $\geq$ 35 years [24]. Similarly, we could not find any significance in terms of mortality (Table 4) $(\mathrm{P}>0.05)$.

In the studies conducted, similar results were obtained for congenital malformations (major and minor anomalies) that were diagnosed antenatal in young and advanced aged patients [15]. Results of our study yielded similar outcomes (Table 5). Israel et al found anomalies by $10 \%$ related to karyotype in the fetuses of women aged over 45 years [25].

First minute Apgar scores were investigated to evaluate perinatal outcomes in newborns. According to the literature, lower Apgar scores were observed in the older pregnant women. In a study from China by Wen et al (2013), advanced age is correlated with low Apgar scores in pregnancies who delivered vaginally [26]. However, in a study by Dulitzki et al, it has been shown that the five minute Apgar score was not affected by maternal age [15]. In our study, no significant difference was found between the groups in terms of the first minute Apgar scores and birth weights (Table 7$)(\mathrm{P}>0.05)$.

No significant difference was found between groups in terms of anemia based on the hemoglobin value during the hospitalization for delivery [6].

An important observation in our study was that $11.7 \%$ of the pregnant women were smoking during their pregnancies, and only $27.5 \%$ of the patients were regularly attending their prenatal visits. In a study by Lamminpaa et al in 2012, 10\% of women were found to smoke during their pregnancies [27]. This demonstrated that better awareness of the society is needed about their controls by physicians.

\section{Conclusion}

There is not any significant difference between pregnancies of advanced maternal aged patients and low-risk patients in terms of preterm birth, delivery method, morbidity, mortality and chronic diseases such as hypertension and diabetes mellitus. Although AMA carries certain risks, advances in especially oocyte donation techniques enable increases of the AMA rates. However, further studies with larger series of patients are needed to elucidate risks of AMA.

\section{References}

1. Fuson J. (2009) Advanced Maternal Age. Retrieved Fabruary 10, 2014, from http://www.lexingtonwomens.com/ pdf/JFusonAdvancedMaternalAge.pdf.

2. Martin LP. Current Obstetric and Gynecology. Boston: Lange Medical Book Series. 1994:322-347.

3. Burdorf A, Brand T, Jaddoe VW, Hofman A, Mackenbach JP, Steegers EA. The effects of work-related maternal risk factors on time to pregnancy, preterm birth and birth weight: the Generation R Study. Occup Environ Med. 2011;68(3):197-204.

4. Jolly M, Sebire N, Harris J, Robinson S, Regan L. The risks associated with pregnancy in women aged 35 years or older. Hum Reprod. 2000;15(11):2433-2437.

5. Ziadeh S, Yahaya A. Pregnancy outcome at age 40 and older. Arch Gynecol Obstet. 2001;265(1):30-33.

6. Altman DG. Practical Statistics for Medical Research. London: Chapman and Hall, 1994: 229-276.

7. Yesiltepe OU, Coskun A. Effectiveness of Comprehensive Nursing Care Relieving Problems of Hospitalized High-Risk Pregnant Women in Bed Rest. TAF Prev Med Bull. 2012;11(2):163-172.

8. Dildy GA, Jackson GM, Fowers GK, Oshiro BT, Varner MW, Clark SL. Very advanced maternal age: pregnancy after age 45. Am J Obstet Gynecol. 1996;175(3 Pt 1):668674.

9. Hansen JP. Older maternal age and pregnancy outcome: a review of the literature. Obstet Gynecol Surv. 1986;41(11):726-742.

10. Smit F, Wijk HV, Gouw C, Duvekot H. Relationship Between Advanced Maternal Age and The Mode ofDelivery. A systematic review. Erasmus J Med. 2012;3(1):34-38.

11. Carolan M, Frankowska D. Advanced maternal age and adverse perinatal outcome: a review of the evidence. Midwifery. 2011;27(6):793-801.

12. Schoen C, Rosen T. Maternal and perinatal risks for women over 44-a review. Maturitas. 2009;64(2):109-113.

13. Astolfi P, Zonta LA. Delayed maternity and risk at delivery. Paediatr Perinat Epidemiol. 2002;16(1):67-72.

14. Tough SC, Newburn-Cook C, Johnston DW, Svenson LW, Rose S, Belik J. Delayed childbearing and its impact on population rate changes in lower birth weight, multiple birth, and preterm delivery. Pediatrics. 2002;109(3):399403.

15. Dulitzki M, Soriano D, Schiff E, Chetrit A, Mashiach S, Seidman DS. Effect of very advanced maternal age on pregnancy outcome and rate of cesarean delivery. Obstet Gynecol. 1998;92(6):935-939.

16. Bae HS. Lifestyle, nutrient intake, iron status, and pregnancy outcome in pregnant women of advanced maternal age. Nutr Res Pract. 2011;5(1):52-59.

17. Cetinkaya MB, Siano LJ, Benadiva C, Sakkas D, Patrizio P. Reproductive outcome of women 43 years and beyond undergoing ART treatment with their own oocytes in two Connecticut university programs. J Assist Reprod Genet. 2013;30(5):673-678.

18. Sauer MV, Paulson RJ, Lobo RA. Pregnancy after age 50: application of oocyte donation to women after natural menopause. Lancet. 1993;341(8841):321-323.

19. Sauer MV, Paulson RJ, Lobo RA. Pregnancy in women 50 or more years of age: outcomes of 22 consecutively established pregnancies from oocyte donation. Fertil Steril. 1995;64(1):111-115.

20. Hoque ME. Advanced Maternal Age and Outcomes of Pregnancy: A retrospective Study From South Africa. Biomedical Research. 2012;23(2):281-285. 
21. Kim TE, Lee SP, Park JM, Whang BC, Kim SY. The Effects of Maternal Age on Outcome of Pregnancy in Healthy Elderly Primipara. Korean J Perinatol. 2009;20(2):146-152.

22. Bianco A, Stone J, Lynch L, Lapinski R, Berkowitz G, Berkowitz RL. Pregnancy outcome at age 40 and older. Obstet Gynecol. 1996;87(6):917-922.

23. Gilbert WM, Nesbitt TS, Danielsen B. Childbearing beyond age 40: pregnancy outcome in 24,032 cases. Obstet Gynecol. 1999;93(1):9-14.

24. Naeye RL. Maternal age, obstetric complications, and the outcome of pregnancy. Obstet Gynecol. 1983;61(2):210216.
25. Israel SL, Deutschberger J. Relation of the Mother's Age to Obstetric Performance. Obstet Gynecol. 1964;24:411417.

26. Wen GF, Jin XY, Wang ZL, Wei Q, Zhou F, Li C, Zhang SY. [Impact of age, single or double, fresh or frozen embryo transfer on pregnancy outcome after in vitro fertilization treatment]. Zhonghua Yi Xue Za Zhi. 2013;93(33):26462649.

27. Lamminpaa R, Vehvilainen-Julkunen K, Gissler M, Heinonen S. Smoking among older childbearing women a marker of risky health behaviour a registry-based study in Finland. BMC Public Health. 2013;13:1179. 